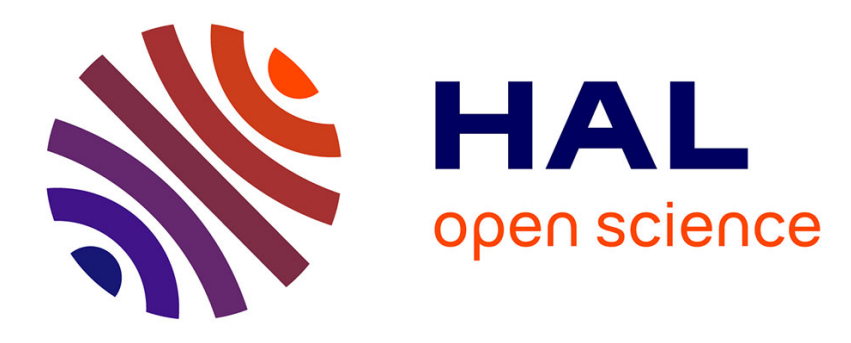

\title{
RACK1 cooperates with NRASQ61K to promote melanoma in vivo
}

Cécile Campagne, Edouard Reyes-Gomez, M.E. Picco, Sophia Loiodice, Paul

Salaun, Jacky Ezagal, Florence Bernex, P.H. Commere, Stéphanie Pons, Diane Esquerre, et al.

\section{To cite this version:}

Cécile Campagne, Edouard Reyes-Gomez, M.E. Picco, Sophia Loiodice, Paul Salaun, et al.. RACK1 cooperates with NRASQ61K to promote melanoma in vivo. Cellular Signalling, 2017, In Press, 10.1016/j.cellsig.2017.03.015 . hal-01529469

\section{HAL Id: hal-01529469 \\ https://hal.science/hal-01529469}

Submitted on 26 Sep 2017

HAL is a multi-disciplinary open access archive for the deposit and dissemination of scientific research documents, whether they are published or not. The documents may come from teaching and research institutions in France or abroad, or from public or private research centers.
L'archive ouverte pluridisciplinaire HAL, est destinée au dépôt et à la diffusion de documents scientifiques de niveau recherche, publiés ou non, émanant des établissements d'enseignement et de recherche français ou étrangers, des laboratoires publics ou privés. 


\title{
RACK1 cooperates with $N R A S^{\mathrm{Q} 61 K}$ to promote melanoma in vivo
}

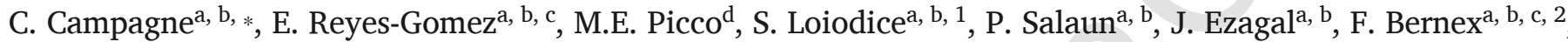

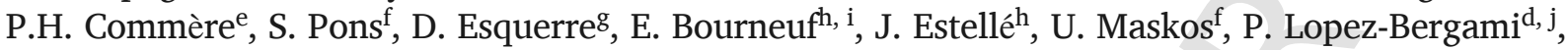 \\ G. Aubin-Houzelstein ${ }^{\mathrm{a}, \mathrm{b}}$, J.J. Panthier ${ }^{\mathrm{a}, \mathrm{b}, \mathrm{k}, 1}$, \&G. Egidy ${ }^{\mathrm{a}, \mathrm{b}, \mathrm{h}, * *}$ \\ ${ }^{a}$ INRA, UMR955 Génétique Fonctionnelle et Médicale, Ecole Nationale Vétérinaire d'Alfort, F-94704 Maisons-Alfort, France \\ ${ }^{\mathrm{b}}$ Université Paris-Est, Ecole Nationale Vétérinaire d'Alfort, UMR955 Génétique Fonctionnelle et Médicale, F-94704 Maisons-Alfort, France \\ ${ }^{\mathrm{c}}$ Université Paris-Est, Ecole Nationale Vétérinaire d'Alfort, Unité d'Embryologie, d'Histologie et d'Anatomie Pathologique, F-94704 Maisons-Alfort, France \\ ${ }^{\mathrm{d}}$ Instituto de Medicina y Biologia Experimental, CONICET, Buenos Aires, Argentina \\ e Plateforme de Cytométrie, Département d'Immunologie, Institut Pasteur, F-75724 Paris, France \\ ${ }^{\mathrm{f}}$ Unité Neurobiologie Intégrative des Systèmes Cholinergiques, UMR 3571, CNRS, Institut Pasteur, F75724 Paris Cedex 15, France \\ ${ }^{g}$ GenPhySE, Université de Toulouse, INRA, INPT, ENVT, Castanet Tolosan, France \\ ${ }^{\text {h }}$ GABI, INRA, AgroParisTech, Université Paris-Saclay, Jouy-en-Josas, France \\ ${ }^{\mathrm{i}}$ LREG, CEA, Université Paris-Saclay, F-78352 Jouy-en-Josas, France \\ ${ }^{\mathrm{j}}$ Centro de Estudios Biomédicos, Biotecnologicos, Ambientales y Diagnostico, Universidad Malmonides, CONICET, Buenos Aires, Argentina \\ ${ }^{\mathrm{k}}$ CNRS URM 3738, USC INRA 2026, F-75724, France \\ ${ }^{1}$ Institut Pasteur, Département de Biologie du Développement et Cellules Souches, Génétique fonctionnelle de la Souris, 25 rue du Docteur Roux, Paris F-75724, France
}

\section{ART ICLE INFO}

\section{Keywords:}

Scaffold

MAPK pathways

Melanocyte

JNK

STAT3

Angiogenesis

\begin{abstract}
A B S T R A C T
Melanoma is the deadliest skin cancer. RACK1 (Receptor for activated protein kinase C) protein was proposed as a biological marker of melanoma in human and domestic animal species harboring spontaneous melanomas. As a scaffold protein, RACK1 is able to coordinate the interaction of key signaling molecules implicated in both physiological cellular functions and tumorigenesis. A role for RACK1 in rewiring ERK and JNK signaling pathways in melanoma cell lines had been proposed. Here, we used a genetic approach to test this hypothesis in vivo in the mouse. We show that Rack1 knock-down in the mouse melanoma cell line B16 reduces invasiveness and induces cell differentiation. We have developed the first mouse model for RACK1 gain of function, Tyr::Rack1-HA transgenic mice, targeting RACK1 to melanocytes in vivo. RACK1 overexpression was not sufficient to initiate melanomas despite activated ERK and AKT. However, in a context of melanoma predisposition, RACK1 overexpression reduced latency and increased incidence and metastatic rate. In primary melanoma cells from Tyr::Rack1-HA, Tyr::NRas ${ }^{Q 61 K}$ mice, activated JNK (c-Jun N-terminal kinase) and activated STAT3 (signal transducer and activator of transcription 3) acted as RACK1 oncogenic partners in tumoral progression. A sequential and coordinated activation of ERK, JNK and STAT3 with RACK1 is shown to accelerate aggressive melanoma development in vivo.
\end{abstract}

\section{Introduction}

Cutaneous melanoma is the deadliest skin cancer. Melanoma has a high metastatic capacity. Despite recent clinical breakthroughs, the majority of metastatic melanoma patients do not survive [1]. The study of a minipig melanoma model revealed an overexpression of RACK1 (Receptor for activated protein kinase C) mRNA in melanoma cells [2].
RACK1 protein is strongly expressed in melanoma cells of primary tumors and metastases in different mammalian species: patients [2], horses [3] and dogs [4]. In sharp contrast, RACK1 is not detected in normal skin melanocytes or in nævi by immunofluorescence [2-4]. Interestingly, RACK1 increased the survival of human melanoma MeWo cells following UV induced-apoptosis. Moreover, inhibition of RACK1 expression using RNA interference was shown to reduce the tumorigenicity of MeWo cells in a xenograft model [5].

\footnotetext{
* Correspondence to: C. Campagne, INRA, UMR955 Génétique Fonctionnelle et Médicale, Ecole Nationale Vétérinaire d'Alfort, F-94704 Maisons-Alfort, France.

** Correspondence to: G. Egidy, GABI, INRA, AgroParisTech, Université Paris-Saclay, 78350 Jouy-en-Josas, France.

Email addresses: cecile.campagne@curie.fr (C. Campagne); giorgia.egidy-maskos@inra.fr (G. Egidy)

1 Current address: Laboratoire de Physiopathologie Orale et Moléculaire, Centre de Recherche des Cordeliers, INSERM UMR1138, F-75006 Paris, France.

2 Current address: RHEM - Institut de Recherche en Cancérologie de Montpellier, INSERM U896, F-34298 Montpellier, France.
} 
RACK1 is a ubiquitous and abundant protein [6]. It is a scaffold containing seven WD40 repeats considered protein-protein interaction platforms. Through its ability to coordinate the interaction of key signaling molecules, RACK1 is thought to integrate various pathways involved in both physiological and tumorigenic cellular functions making it a signaling hub [7]. Yet, the extent to which the multiple binding partners of RACK1 are coordinated has not been much tested in vivo. In an attempt to alter RACK1 levels in mammals, the group of S. Biffo obtained one mouse line with a hypomorphic Rack1 allele. While homozygosity for that hypomorphic Rack1 allele resulted in a lethal phenotype, heterozygous adult mice showed no major phenotype except for a belly spot and hypopigmented tail and paws [8], typical features of a developmental defect in melanoblast migration.

A role for RACK1 in the crosstalk between ERK (Extracellular signal-regulated kinase) and JNK (c-Jun N-terminal kinase) signaling in melanoma was proposed to set up a feed forward mechanism triggering tumoral progression [9]. In the light of these in vitro data, we hypothesized that gain of function of RACK1 targeted to melanocytes in the context of NRas constitutive activation would accelerate melanomagenesis by strengthening converging tumoral signaling.

As for other solid cancers, cutaneous melanoma development is considered as a multistep process. Melanomagenesis requires a combination of gain of function mutations in oncogenes and loss of function mutations in tumor suppressor genes [10]. The first spontaneous metastasizing melanoma model harbored the $N R a s^{Q 61 K}$ mutation in a deleted $C d$ $k n 2 a$ background [11]. To test whether an overexpression of RACK1 was sufficient to trigger melanoma, we created Tyr::Rack1-HA transgenic mice in which a hemaglutinin (HA) epitope-tagged-RACK1 is expressed off the Tyrosinase promoter. We show here that RACK1 overexpression is not sufficient to trigger nevi or melanomas despite ERK and AKT activation. Yet, in a context of melanoma predisposition, RACK1 melanocytic overexpression reduced latency and increased incidence and metastatic rate. We found activated JNK and STAT3 as partners of RACK1 in melanomagenesis.

\section{Materials and methods}

\subsection{Mice and genotyping}

Mouse Rack1 cDNA was tagged with HA by PCR before insertion in a pBSK-UPT-Tyr-SV40 plasmid [12]. Micro-injection of the linearized vector was made in B6CBAF1/J fertilized oocytes. Tyr::Rack1-HA transgenic founders were characterized by Southern blot analysis and PCR genotyping. Data come from the 7th backcross onwards on C57BL/6J background. The Pax $3^{G F P}$ and -Cdkn2a alleles and Tyr::NRas ${ }^{Q 61 K}$ transgene have been backcrossed onto the C57BL/6J background for $>15$ generations [13]. Animal care and use for this study were approved by the ethical board of Alfort Veterinary School in accordance with European Union Standards (agreement number 16, notice 14/02/12-4). To identify the Tyr::Rack1-HA transgene, the following primers were used: forward: 5 '-gtcgacatgaccgagcagatgacc- $3^{\prime}$ and reverse $5^{\prime}$-tacatggttgcgccatctgcgecgcgggtaccaatag- $3^{\prime}$. PCR conditions were $30 \mathrm{~s}$ at $94{ }^{\circ} \mathrm{C}, 30 \mathrm{~s}$ at $65{ }^{\circ} \mathrm{C}, 30 \mathrm{~s}$ at $72{ }^{\circ} \mathrm{C}$ for 30 cycles and a final extension step at $72{ }^{\circ} \mathrm{C}$ for $10 \mathrm{~min}$. The other genotyping conditions were as described [13].

\subsection{Histologic analysis and immunofluorescence in mouse samples}

Complete necropsy and systematic pathological analysis were performed on all mice as described [14]. Immunofluorescence was performed with mouse monoclonal anti-RACK1 (Transduction Laboratories, dilution 1:150, BD Biosciences, Le Pont de Claix, France), chicken polyclonal anti-GFP (Abcam, 1:600, Paris, France), mouse monoclonal anti-HA (Covance, 1:600, Rueil-Malmaison, France), rabbit anti-cytokeratin5 (Thermo Scientific, 1:100, Fisher Scientific, Illkirch, France) and rabbit polyclonal anti-pERK (Thr202/Tyr204, 1:200) and anti-pAKT (Ser473, 1:50) (Cell Signaling, Ozyme, St Quentin, France) and rabbit anti-ERK 1:100, goat anti-Ki67 1:100, anti-STAT3, anti-JNK (D-2) (Santa Cruz, Heidelberg Germany) antibodies. Nuclear counter-staining was achieved with 4',6'-diamidino-2-phenylindole (DAPI) (1:1000, Invitrogen). Sections were examined with a Zeiss Axio Observer Z1M ApoTome microscope (Carl Zeiss S.A.S., Le Pecq, France). Controls without the first antibodies showed no unspecific labeling. Images were processed with the AxioVision computer program version 4.6 (Carl Zeiss). Figures are representative of the skin samples evaluated ( $n>8$ for each mouse line). All images shown are individual sections of $\mathrm{z}$ series stack. Final figures were assembled with Adobe Photoshop CS3 (Adobe Systems; USA). Quantification of Ki67/GFP positive nuclei was performed on images obtained at $40 \times$ in regions positive for Ki67, counting at least 30 $\mathrm{GFP}^{+}$cells per field, 2 fields per mouse, 6 mice per genotype.

\subsection{Fluorescent activated cell sorting (FACS), cell culture, soft agar assays and immunofluorescence}

Skin melanocytes and melanoma cells from primary tumors $(n=6)$ or metastases (lymph nodes $n=6$; lung $n=4$; liver $n=1$; brain $\mathrm{n}=1$ ) were isolated, FACS-sorted and cultured as previously described [13]. B16 melanoma cell line was grown in DMEM medium with $10 \%$ fetal calf serum and penicillin/streptomycin. All cells were grown at $37{ }^{\circ} \mathrm{C}$ under $5 \% \mathrm{CO}_{2}$ at $\mathrm{pH} 7.0-7.1$. ERK inhibitor U0126, $5 \mu \mathrm{M}$ and $10 \mu \mathrm{M}$, and JNK inhibitor SP600126 $20 \mu \mathrm{M}$ (Sigma-Aldrich, Saint-Quentin Fallavier, France) were incubated for 24 or 48 h. Human cells UACC903 were cultured as previously described [9]. Soft agar tests were made in 96-well plates as described [13].

For immunofluorescence on cells plated onto coverslips, fixation lasted $15 \mathrm{~min}$ in $2 \%$ PFA and permeabilization with ice-cold methanol, $10 \mathrm{~min}$. Immunolabeling on cells or agar slices was performed like in tissue section with the omission of the antigen retrieval step. Antibodies used were mouse monoclonal anti-Ki67 (1:100, Novocastra, Newcastle upon Tyne, UK), rabbit polyclonal anti-pPKC $\alpha / \beta_{\text {II }}$ (Thr638/641, 1:100), anti-pJNK (pSAPK Thr183/Tyr185, 1:25), anti-pSTAT3 (Tyr705, 1:100) (Cell Signaling) and as above.

\subsection{RNA interference and transduction}

Mouse Rack1 shRNA sequence (ID\# 61854) corresponding to a sequence inside exon 2, was obtained from Ambion (Invitrogen): GGTCACTCCCACTTCGTTATT and the scramble sequence used was GTCACTCACCCTTCGGTTATT [15]. Lentiviral vectors with GFP reporter of infections were produced as previously described [16]. Three Stat3 shRNA (ID\# 424803, 424802, 641819) were obtained from Open Biosystem (Thermo Fisher Scientific) as lentiviral vectors. Transduction was performed with at $0.45 \mathrm{ng} / \mu \mathrm{l}$ of lentiviral titer in presence of polybrene. RNA was collected on the third day.

\subsection{RNA extraction and quantitative RT-PCR}

RNA extractions were performed on 20,000 FACS-sorted cells following RNA XS kit manufacturer instructions (Macherey Nagel, Germany) as described [13]. RNA sequencing (RNA-seq) on shScramble and shRack1-treated melanocytes, primary melanoma from Tyr::NRas*; $P a x 3^{G F P /+}$ cells with or without Tyr::Rack1-HA was performed on technical triplicates of viral infection. Libraries were prepared by selecting polyadenylated mRNA using the TruSeq RNA Sample Prep Kit (Illumina, San Diego, CA). When performed on plated infected cells, RNA was prepared from $10^{6}$ cells in 6 well plates. qPCR assays on cDNA from primary cells infected with shRack1 were performed using TATAA Granscript cDNA Supermix for reverse transcription and TATAA SYBR 
GranMaster mix on a Light Cycler480 qPCR instrument (Roche) (TATAA Biocenter, Czech Republic). Actb, Gapdh, Tubb5 and Rnp2 were used as reference genes. Experiments were carried out at least twice in triplicates.

\subsection{Protein extractions, immunoprecipitation, Western-blot analyses and JNK kinase assay}

Experiments were performed as described [13], at least twice. Antibodies used were anti-tubulin (Cell Signaling), anti-STAT3, anti-JNK (D-2) (Santa Cruz, Heidelberg Germany) and the same as above. JNK immunokinase assays were performed with endogenous JNK as previously described [5].

\subsection{Statistical methods}

Error bars in the figures represent standard errors of the mean. The two-tailed Student's $t$-test or nonparametric Mann-Whitney $U$ test were used to assess differences between groups. A $P$-value $<0.05$ was considered as statistically significant $\left(* * * P<0.001,{ }^{* *} P<0.01\right)$.
Other details regarding transgenesis construct, histological analysis, immunofluorescence in skin samples and cells, RNA interference and transduction, quantitative RT-PCR, RNA seq or Western blot are available in the supplementary section.

\section{Results}

\subsection{Effect of RACK1 knock-down on metastatic melanoma cell clonogenicity and differentiation}

To test the importance of RACK1 in melanoma development we developed a Rack1 shRNA lentivirus by inserting a previously validated sequence [15] into a backbone allowing visual control of infection [16] (Fig. 1a). The murine melan-a cell line, which is a nontransformed immortalized melanocytic line, and the highly metastatic B16 melanoma line were used to test RACK1 knock-down. With a transduction efficacy around 90\%, RACK1 protein was efficiently reduced by shRack1 as evaluated by immunofluorescence and Western blot analyses without affecting unrelated proteins like Tubulin, three days post transduction of metastatic B16 cells (Fig. 1a). However, B16-shRack1 cells were pro-

\section{a}

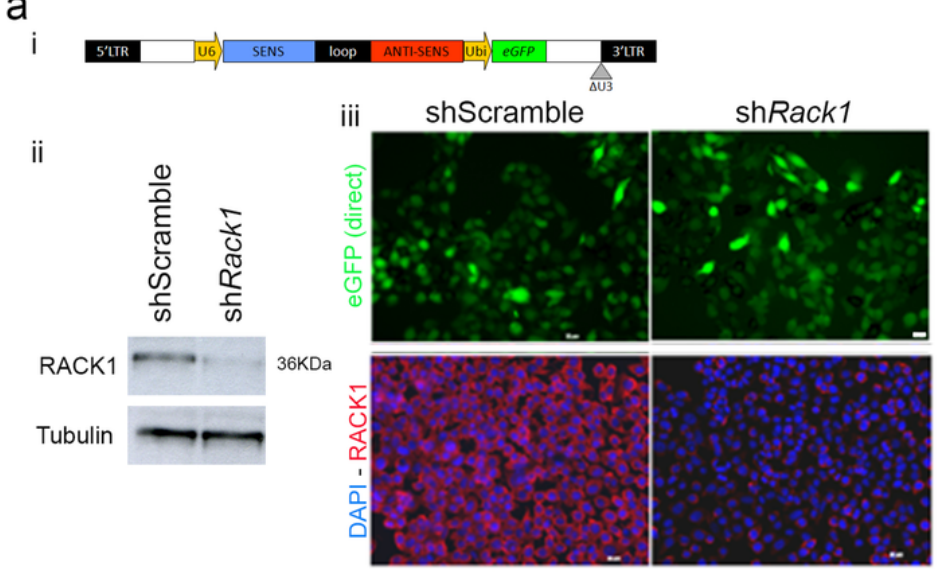

C

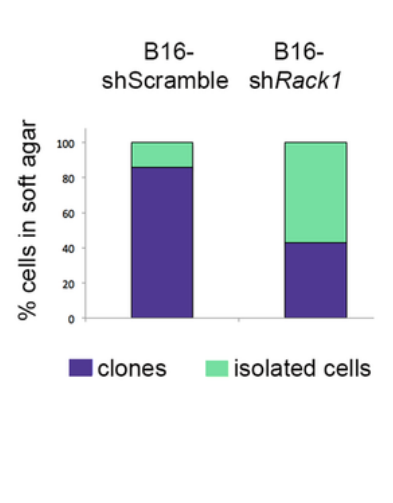

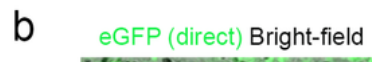

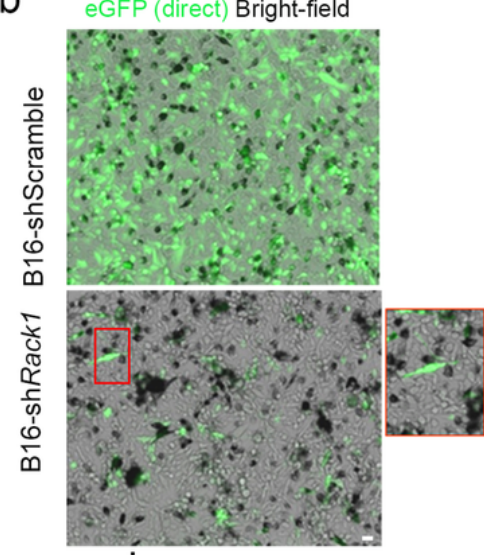

$\mathrm{d}_{\mathrm{i}}$

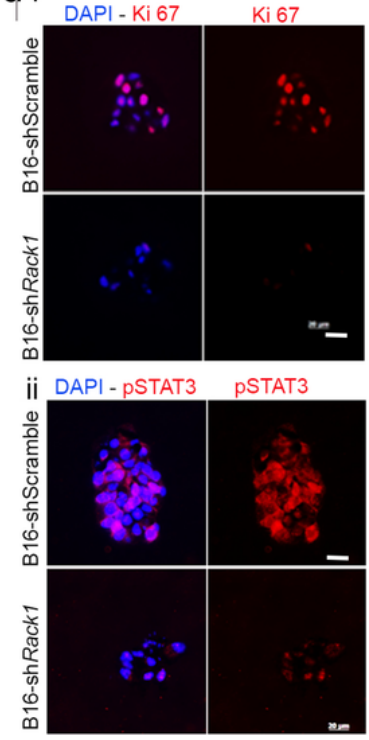

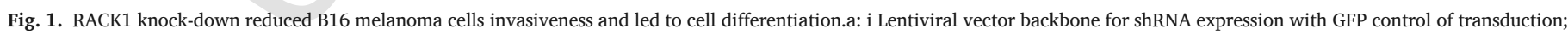

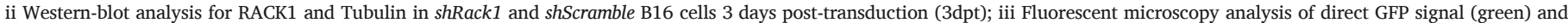

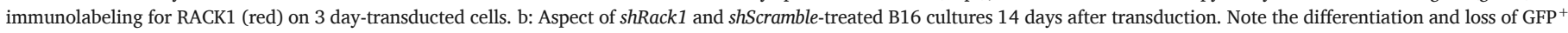

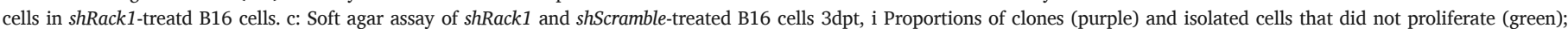

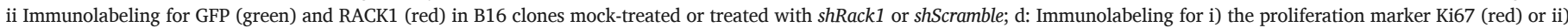

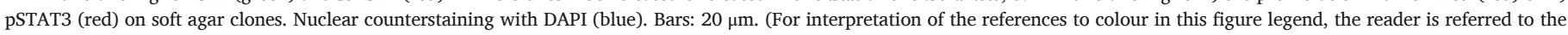
web version of this article.) 
gressively lost from day 10 to day 20 post transduction, being replaced by cells not transduced, hence not expressing the shRNA (Fig. 1b). Remaining fluorescent B16-shRack1 cells showed a differentiated phenotype. They switched from the typical rounded B16 shape to a melanocyte-like shape with dendritic extensions and higher melanin content (Fig. 1b), as did melan-a cells (Fig. S1).

We assessed the effect of RACK1 silencing on anchorage-independent cell growth of 3 day transduced cells. Only $40 \%$ of B16-shRack1 cells formed clones in soft agar compared to 86 and $88 \%$ in B16-shScramble and B16-mock cells, respectively ( $\chi^{2}$ test; $\left.P<0,0005\right)$ (Fig. 1c). Furthermore, the B16-shRack1 clones were smaller than the controls (Fig. 1c). This reduced size of B16-shRack1 clones relates to a sharp reduction of Ki67 and pSTAT3 staining (Fig. 1d).

\subsection{Overexpressed RACK1 in melanocytic cells from the Tyr::NRas ${ }^{Q 61 K}$ melanoma model}

We next determined RACK1 expression in the Tyr::NRas ${ }^{Q 61 K}$; Cd$k n 2 a^{-/-}$mouse melanoma model, referred to as Tyr::NRas* thereafter. These mice carry a melanocyte-targeted $N R a s^{Q 61 K}$ transgene which leads to constitutive ERK activation [11]. Tyr::NRas* mice develop early dermal melanocytic proliferation responsible for skin hyperpigmentation, which can eventually progress to a malignant lesion [14]. We have shown that introduction of the $\operatorname{Pax}^{\mathrm{GFP}}$ allele allows the identification of fluorescent melanocytic cells in the skin without affecting melanoma development $[13,17]$. Immunofluorescence on cutaneous melanomas showed a cytoplasmic RACK1 signal in $\mathrm{GFP}^{+}$cells (Fig. 2a). RACK1 was immunodetected in all lesions from Tyr::NRas*; Pax $3^{G F P /+}$ and Tyr::NRas* mice.

We also tested melanoma-free skin. In control $\mathrm{Pax} 3^{\mathrm{GFP} /+} ; \mathrm{Cdkn} 2 \mathrm{a}^{-/-}$ mice, RACK1 protein was highly expressed in the cytoplasm of keratinocytes, here considered as positive controls. In contrast, melanocytes identified as $\mathrm{GFP}^{+}$cells were negative for RACK1. We excluded the possibility that melanocytes displayed membrane RACK1 signal with triple immunostaining against RACK1, GFP and cytokeratin 5 (CK5), a marker of basal keratinocytes. Instead, in Tyr::NRas*; Pax $3^{\mathrm{GFP} /+}$ mice, skin sections displayed a specific cytoplasmic RACK1 signal in $\mathrm{GFP}^{+}, \mathrm{CK}^{-}$melanocytes (Fig. 2b). Follicular, interfollicular and dermal melanocytes displayed this specific melanocytic RACK1 signal (Fig. S2). To test whether RACK1 overexpression occurred at the transcript level, $\mathrm{GFP}^{+}$melanocytes were sorted by FACS from neonatal skins. Higher Rack1 mRNA levels were observed in Tyr::NRas;; $\mathrm{Pax}^{\mathrm{GFP} /+}$ melanocytes isolated from neonatal skin compared to $\mathrm{Cd}$ $k n 2 a^{-/-} ; \mathrm{Pax}^{\mathrm{GFP} /+}$ control pup littermates (Fig. 2c). Thus, ERK activation together with RACK1 overexpression is associated with melanoma and melanoma predisposition in this model.

To study signaling associated with the progression stages, we established primary cultures from neonatal skin, primary tumor, locoregional metastasis, and distant metastasis which, as expected, were pERK ${ }^{+}$according to $N R a s^{Q 61 K}$ expression when assayed by immunofluorescence and Western blot (Fig. 2d) [13]. In these cells, overexpression of Rack1 mRNA (Fig. 2e) and high RACK1 protein level were identified (Fig. 2f). Interestingly, a $60 \mathrm{kDa}$ band in addition to the predicted $36 \mathrm{kDa}$ band was revealed in tumor cells compared to melanocytes (Fig. 2f). Denaturing conditions did not support dimerization of RACK1 (not shown). Inhibition of MEK1 with U0126 did not alter RACK1 reactivity in melanoma cells (Fig. S3).

\subsection{Activated ERK and transiently increased skin melanocytes in pups with} Rack1 gain of function in melanocytes

To address a causative role of RACK1 in melanoma development, we generated Tyr::Rack1-HA transgenic mice. We used the $6.1 \mathrm{~kb}$ promoter sequence of the mouse Tyrosinase gene in combination with the
$3.6 \mathrm{~kb}$ distal control region [12] to target the expression of the mouse Rack1 gene (MGI:101849) that encodes RACK1, tagged by HA, to the melanocytic lineage (Fig. 3a). RACK1-HA expression from the Tyr::Rack1-HA transgene was detected when transfected into B16 cells in vitro (Fig. 3a).

Five Tyr::Rack1-HA transgenic founders were obtained using classical transgenesis (Fig. 3aiii). All founders were viable, fertile and reached adulthood without displaying any overt phenotype. Three lines were established with offspring from three distinct founders and analysed in detail. In order to easily identify melanocytes, the three lines were crossed with $P a x 3^{G F P /+}$ mice. Melanocytes were FACS-sorted on GFP from back skin of 3 day-old pups for each transgenic line and quantitative RT-PCR assays were performed. As expected, Rack1 mRNA levels in melanocytes were higher in Tyr::Rack1-HA; Pax $3^{\text {GFP/+ }}$ mice than in Pax $3^{G F P /+}$ littermates in each transgenic line (Fig. 3b). Rack1/Actb ratios were comparable to ratios measured in the Tyr::NRas* mice.

Protein expression of RACK1 in melanocytes in furry and glabrous skin was assessed by immunofluorescence (Fig. 3c, Fig. S4). In Tyr::Rack1-HA; Pax3 ${ }^{G F P /+}$ melanocytes, GFP and HA protein signals were colocalized (Fig. 3c, third line). Moreover, a specific cytoplasmic RACK1 signal was detected in GFP and HA-positive melanocytes (Fig. 3c). Triple immunostaining against RACK1, GFP and CK5 confirmed the melanocytic origin of the RACK1 signal (Fig. 3c, fourth line). Thus, in our three Tyr::Rack1-HA transgenic mouse lines, Rack1 mRNA was overexpressed and RACK1 protein was detected in melanocytes. This excluded a role of the integration site of the transgene.

RACK1 was reported to associate with the core kinases of the ERK pathway and RACK1 reduction resulted in lower ERK activity while RACK1 overexpression produced an increased ERK activation $[18,19]$. We tested ERK activation in melanocytes of transgenic Tyr::Rack1-HA; $P a \times 3^{G F P /+}$ and $P a x 3^{G F P /+}$ control mice by immunostaining (Fig. 3d). In control Pax $3^{\mathrm{GFP} /+}$ melanocytes, pERK signal was hardly detected. Instead, in Tyr::Rack1-HA; Pax $3^{G F P /+}$ melanocytes, nuclear GFP and pERK signals were co-localized. Besides, pERK signal was also identified in keratinocytes. Noteworthy, total ERK expression was equivalent in both sample types (Fig. S5). We checked whether the PI3K/AKT pathway was also activated in the skin of Tyr::Rack1-HA transgenics. Nuclear pAKT signal was detected as well as in Tyr::NRas*, Pax $3^{\mathrm{GFP} /+}$ skins, as opposed to $P a x 3^{G F P /+}$ skin (not shown). These data suggest that RACK1 overexpression associated with ERK and AKT activation. We studied whether this PERK immunodetection corresponded to a proliferative signal translating efficient ERK activation. Tyr::Rack1-HA; Pax $3^{\text {GFP/+ }}$ skin biopsies presented $26 \%$ more $\mathrm{GFP}^{+}$cells than $\mathrm{Pax} 3^{\mathrm{GFP} /+}$ skins (Fig. 3e). Yet, no coat or skin hyperpigmentation was visible in any of the mouse lines. Over 17 months of follow-up, no melanocytic lesions were detected in any of the three transgenic lines ( $\mathrm{r}>15$ mice/line). In addition, the morphology of the skin was normal indicating that RACK1 overexpression alone was not sufficient to drive melanoma development (Fig. S6).

\subsection{Accelerated melanoma appearance with RACK1-HA expression in a context of Tyr::NRas* melanoma predisposition}

Melanoma penetrance is not complete in the Tyr::NRas* model [11]. In our colony, 33\% of mice develop melanoma [14]. To assess the effects of RACK1 expression in a genetic background predisposing to melanoma, we produced Tyr::Rack1-HA; Tyr::NRas*; Pax $3^{\text {GFP/+ }}$ mice for the three Tyr::Rack1-HA independent transgenic lines. These mice developed melanocytic lesions ranging from benign to malignant tumors [14] (Fig. 4a). No differences in latency and incidence were seen between the three transgenic lines. Nevertheless, $78 \%$ of the Tyr::Rack1-HA; Tyr::NRas*;Pax $3^{\text {GFP/+ }}$ mice in each line showed reduced latency within about 10 months, mean 7.5 months (Mann-Whitney test; $P<0.002$ ) (Fig. 4b). Besides, 55\% of mice developed 

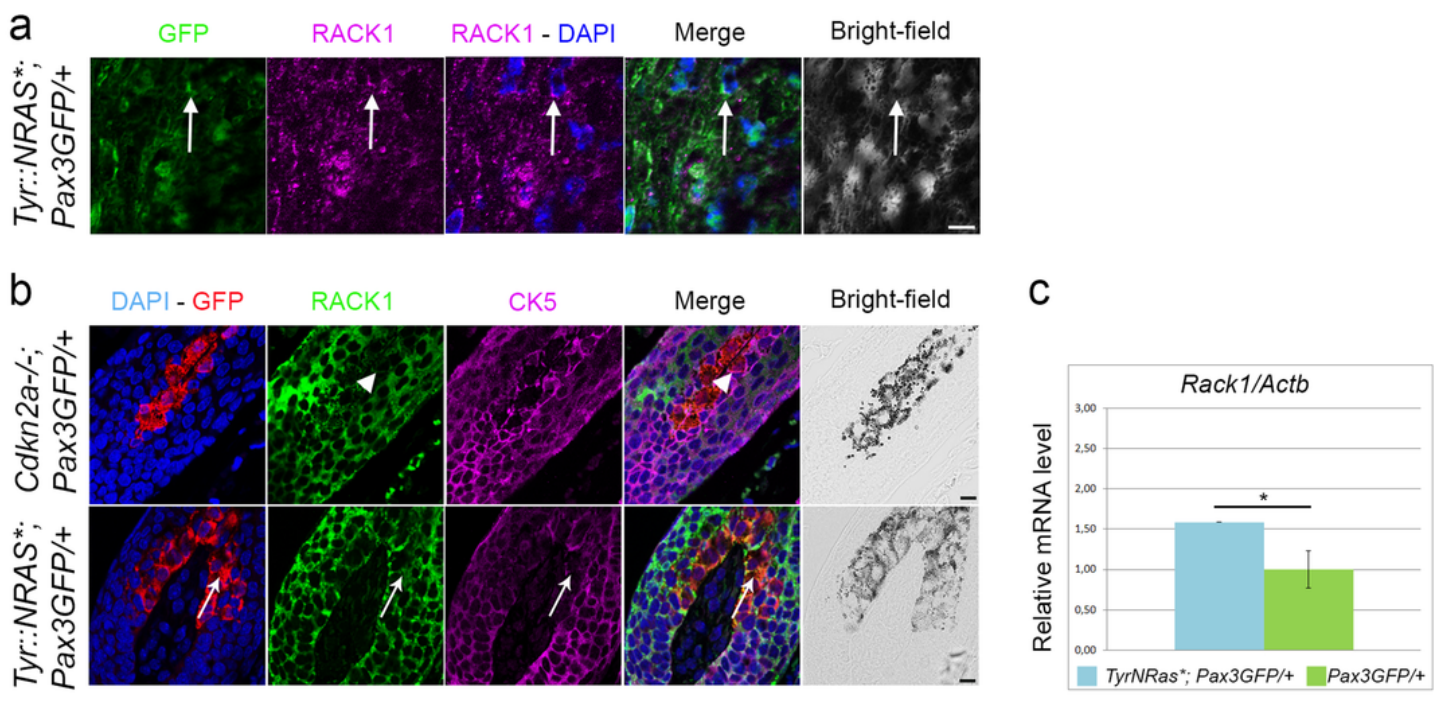

d i

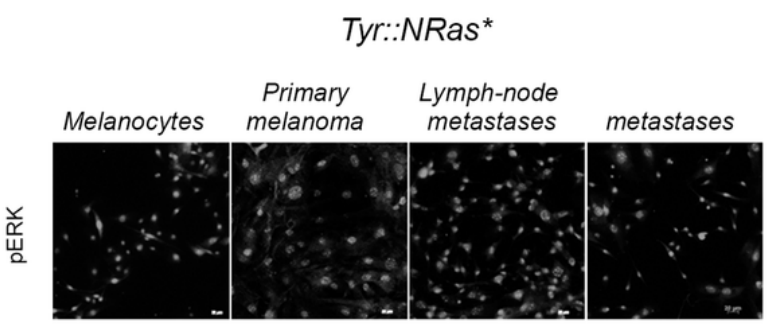

ii

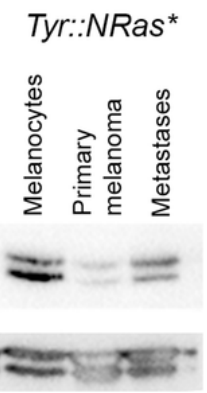

e

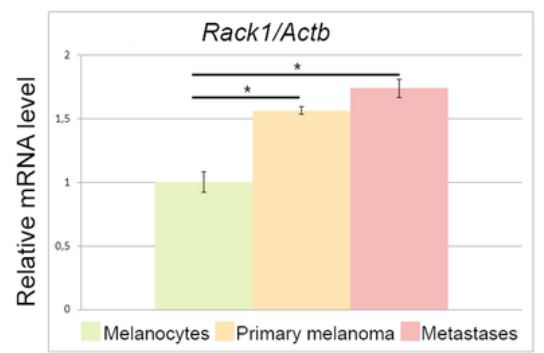

f

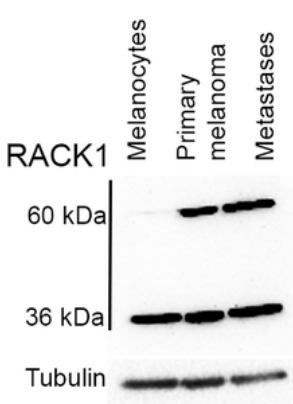

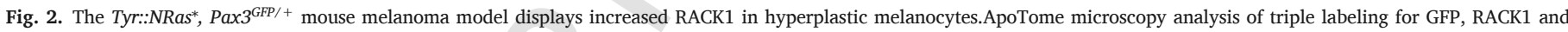

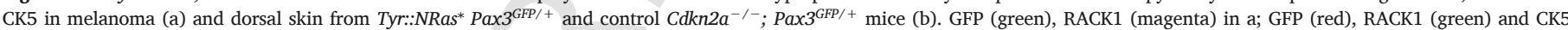

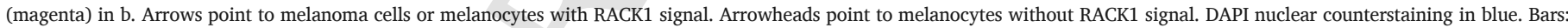

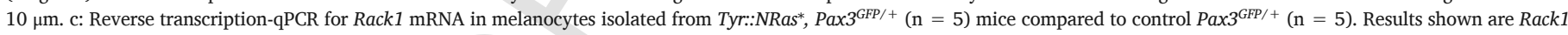

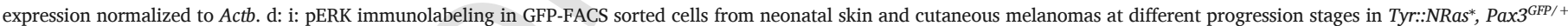

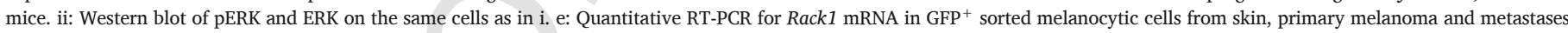

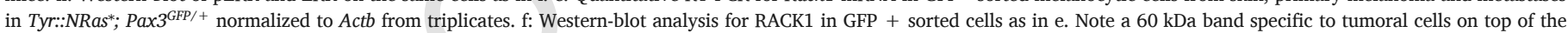
$36 \mathrm{kDa}$ expected band. ${ }^{*} P<0.05$. (For interpretation of the references to colour in this figure legend, the reader is referred to the web version of this article.)

melanomas, indicating a clear increase in incidence of primary cutaneous malignant lesions ( $\mathrm{n}=22 / 31, \chi^{2}$ test; $P<0.05$ ) (Fig. 4a). Moreover, distant metastases were more frequently identified in Tyr::Rack1-HA; Tyr::NRas*; Pax $3^{\text {GFP/+ }}$ mice $(55 \%, \mathrm{n}=12 / 22)$ compared to Tyr::NRas*; Pax3 $3^{\text {GFP } /+}$ mice $(36 \%, \mathrm{n}=9 / 25)$ (Fig. 4c). Histological analysis of the lesions detected no differences between Tyr::Rack1-HA lesions and those of control Tyr::NRas*; Pax $3^{\text {GFP/+ }}$ littermates (Fig. 4a). However, when the proliferation status of melanocytic cells was analysed using Ki67 labeling, Tyr::Rack1-HA bearing melanomas presented a higher index than controls (Fig. 4d) $(32.9 \pm 17.8$ versus $22.3 \pm 8.1$ respectively, Student's $t$-test; $P<0.05)$.

The higher incidence, lower latency and higher frequency of mitosis provide the first in vivo evidence of a contribution of RACK1 to melanoma development. Histological data point to an acceleration of the proliferative status of the lesions.

\subsection{JNK and STAT3 as oncogenic partners of RACK1 in melanoma development}

To investigate the clinical advantage conferred by the overexpression of RACK1 in the Tyr::NRas* model, we explored candidate proteins related to metastasis. STAT3 activation has been shown to promote metastasis in melanoma [20]. To test whether PKC and JNK activation were involved in melanomagenesis induced by activated NRAS as modeled in vitro [9], we isolated primary melanocytic cells from neonatal skin and at different stages of tumoral progression from Tyr::NRas*; $P a \times 3^{G F P /+}$ mice. pPKC $\alpha / \beta_{\text {II }}$, pJNK and pSTAT3 were analysed by immunofluorescence. Phosphorylation of $\mathrm{PKC} \alpha / \beta_{\mathrm{II}}$ was detected both in melanocytes and in tumoral cells, independently of their tumoral progression stage. pJNK, instead, started to be observed in 

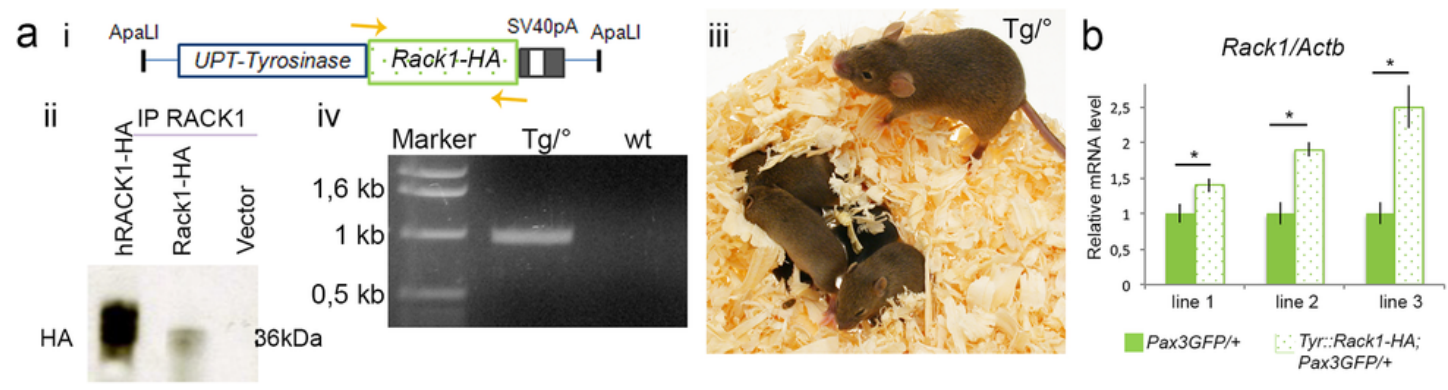

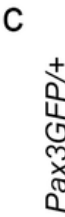
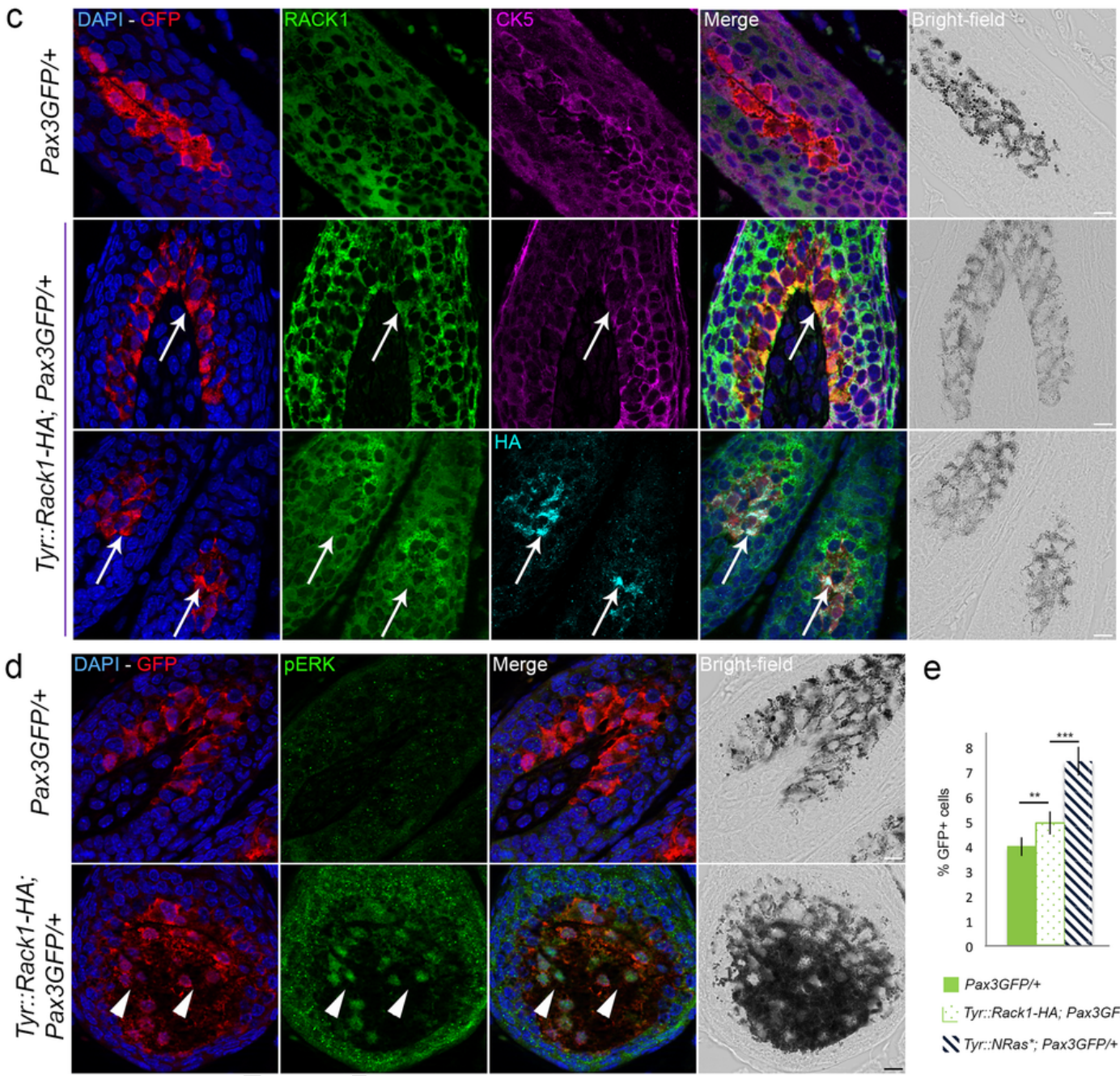

e

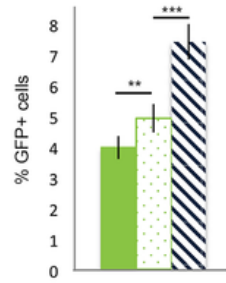

Pax3GFP/+

$\therefore$ Tyr:Rack1-HA; Pax3GFP/+

NTyr:NRas*; Pax3GFP/+

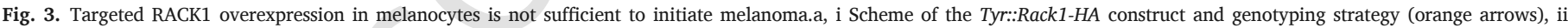

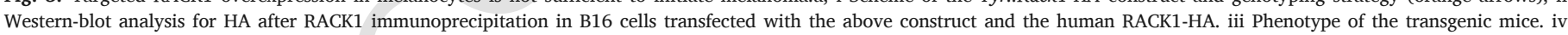

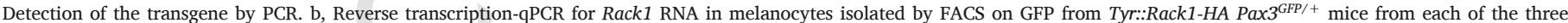

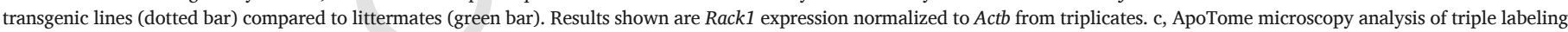

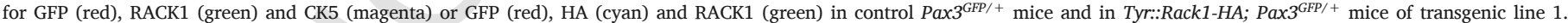

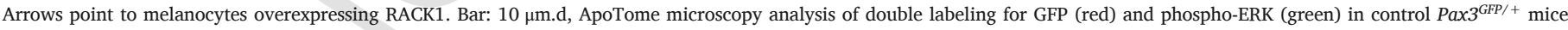

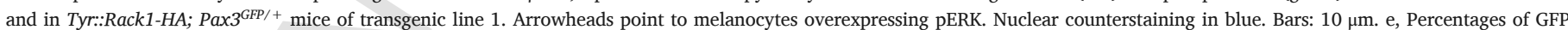

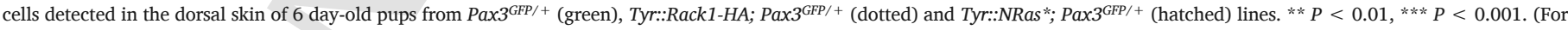
interpretation of the references to colour in this figure legend, the reader is referred to the web version of this article.)

melanoma cells from primary lesions and was stronger in cells isolated from metastases (Fig. 5a). While no signal was visible on neonatal melanocytes and only a small number of primary cutaneous melanoma cells showed a signal, a high proportion of metastatic cells were found positive for pSTAT3 (Fig. 5a). RACK1 cytoplasmic immunoreactivity instead is detected in all cells (Fig. 5a).

Next, we analysed whether JNK and RACK1 interacted in Tyr::NRas* melanoma cells. Positive interaction was shown between
pJNK and RACK1 by Western blot analysis after RACK1 immunoprecipitation in primary melanoma and metastases. RACK1-pJNK interaction occurred at basal levels, without specific induction suggesting constitutive activation of JNK in these cells (Fig. 5b). We also validated the activation of STAT3 in melanoma cells by Western blot as well as its binding to RACK1, after RACK1 immunoprecipitation. Despite the activation of STAT3 in primary melanoma cells RACK1-pSTAT3 interac- 
a

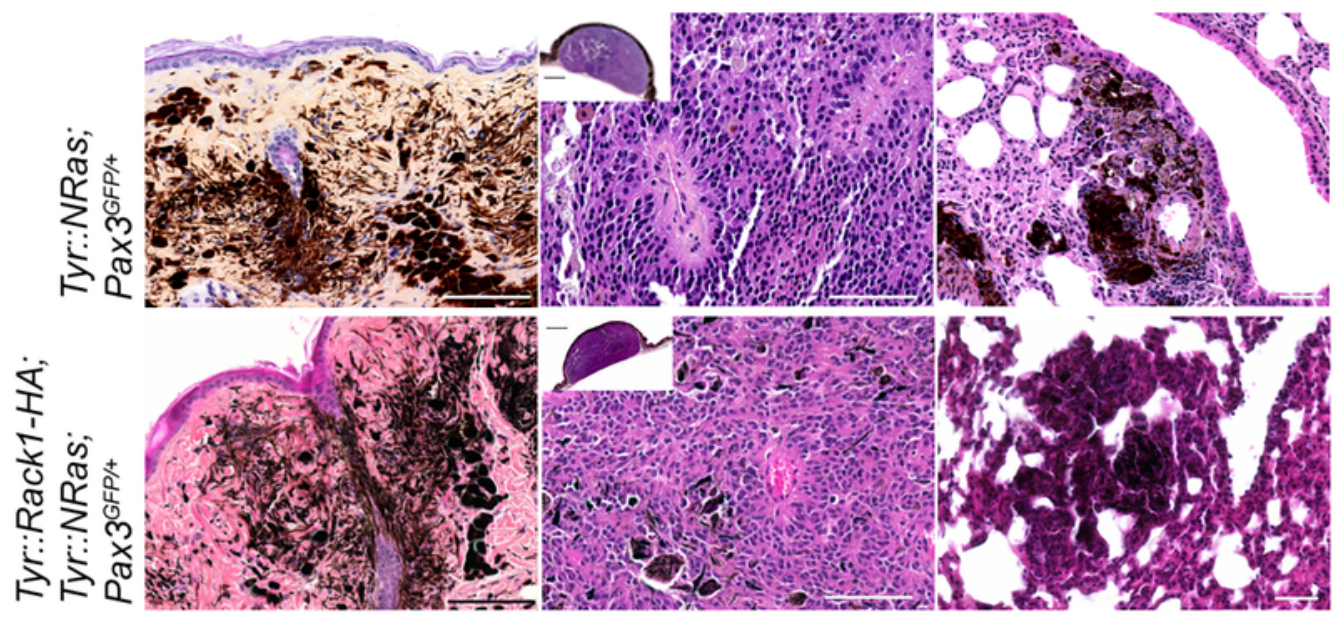

b

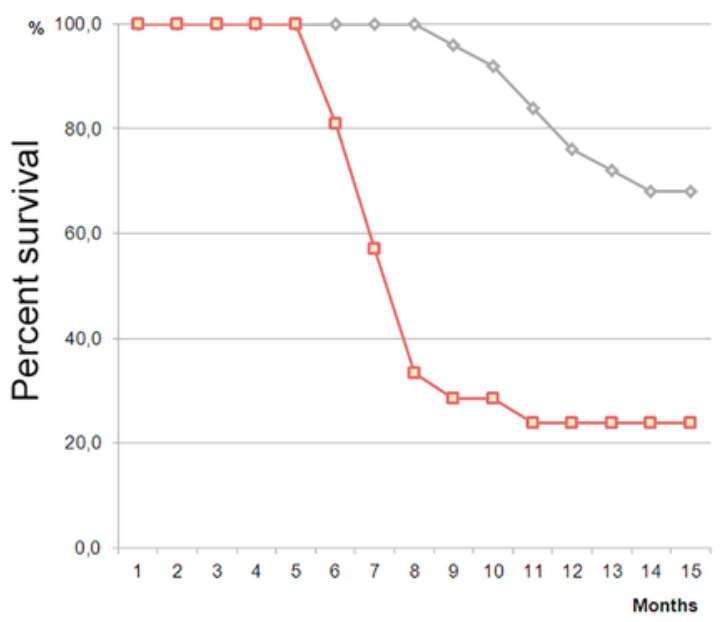

C

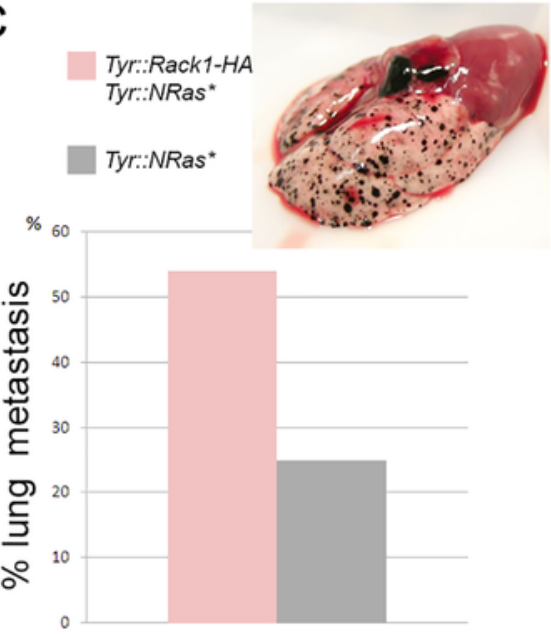

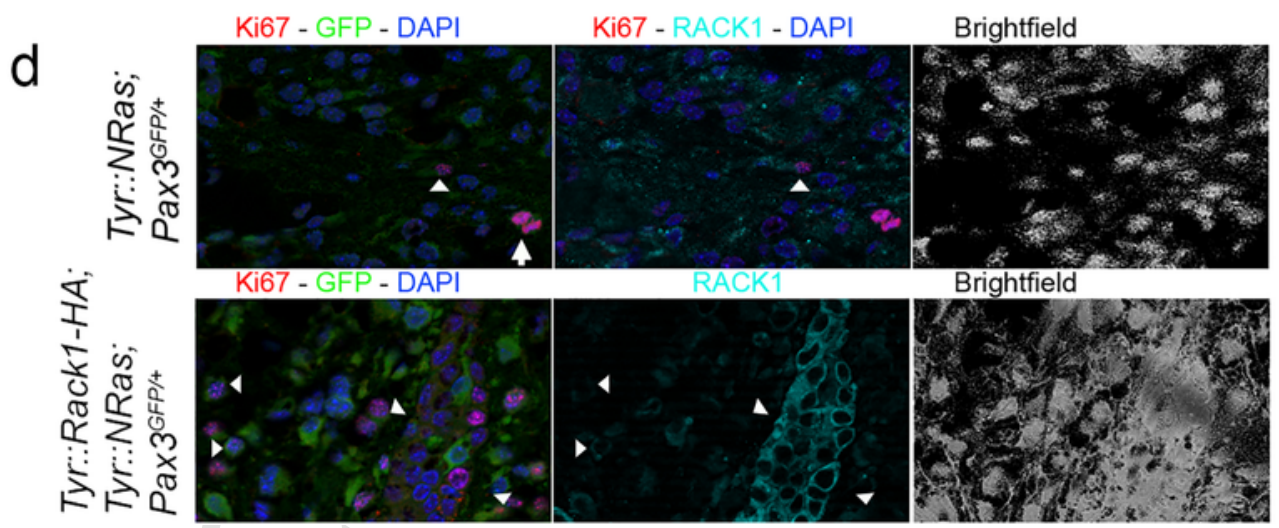

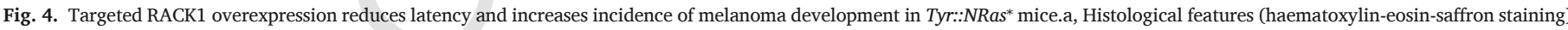

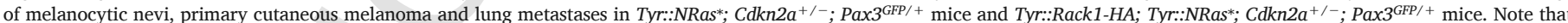

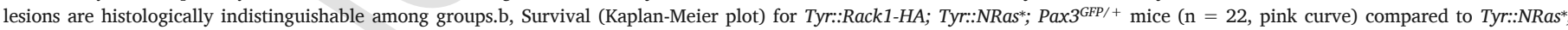

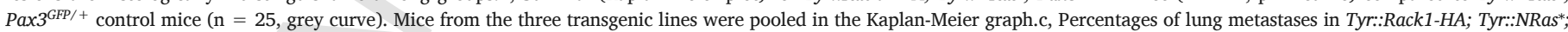

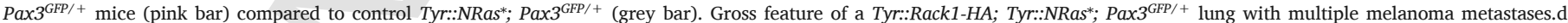

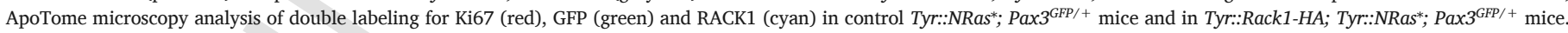

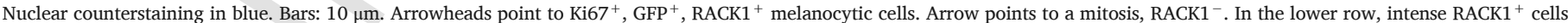
are keratinocytes. (For interpretation of the references to colour in this figure legend, the reader is referred to the web version of this article.) 


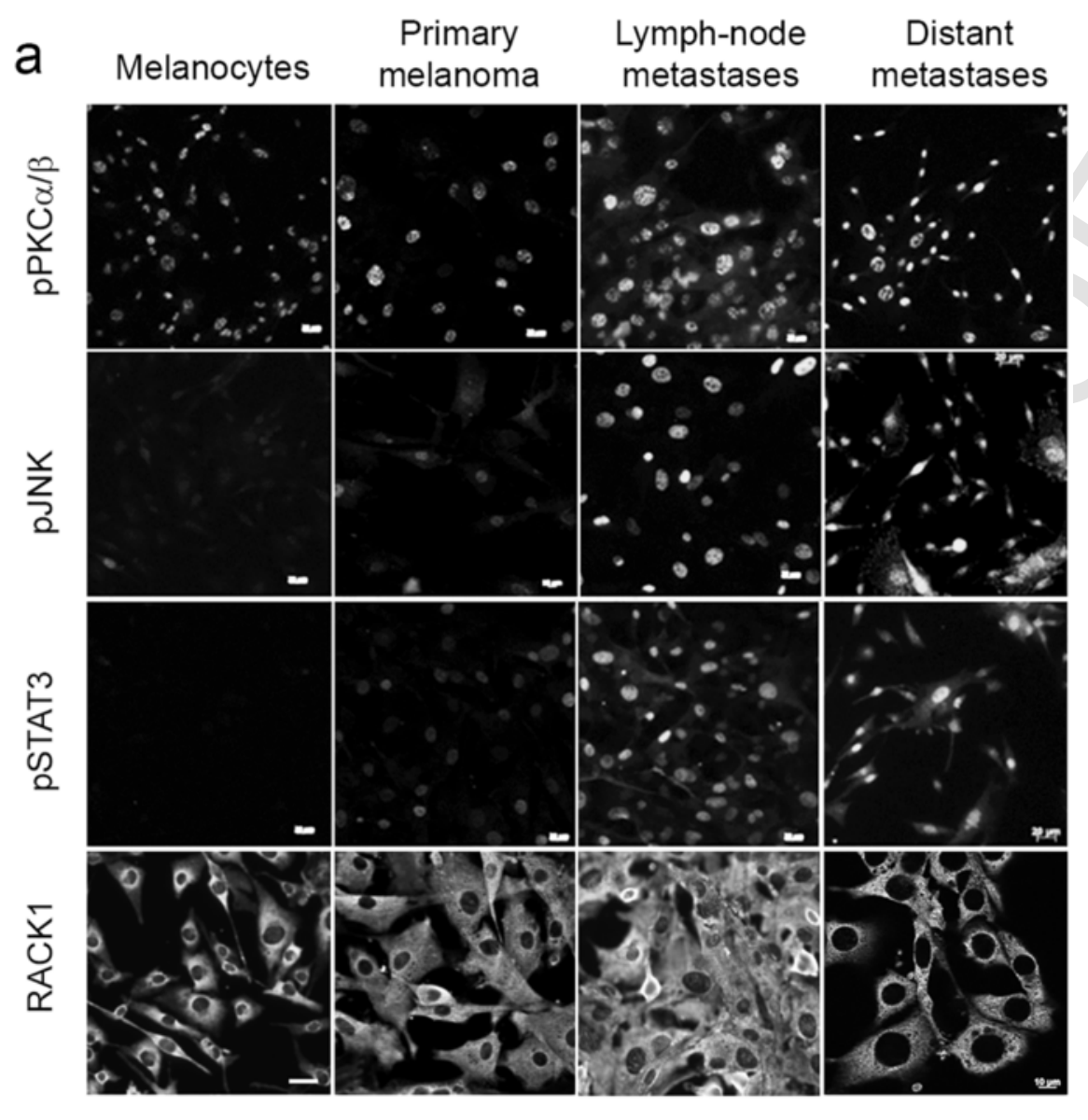

b

\section{IP RACK1 IB pJNK}

IB RACK1

\section{Lysate pJNK}

Tubulin
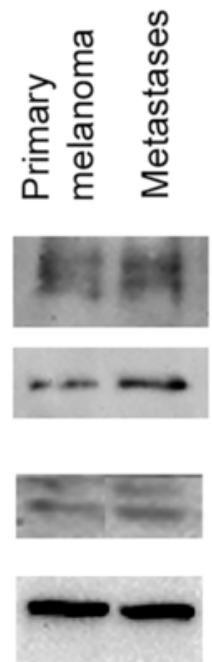

IP IgM anti-RACK1 IgM

IB pJNK
C

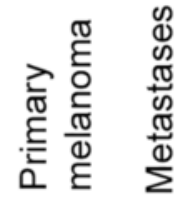

\section{IP RACK1} IB PSTAT3

\section{Lysate}

pSTAT3

STAT3

Tubulin
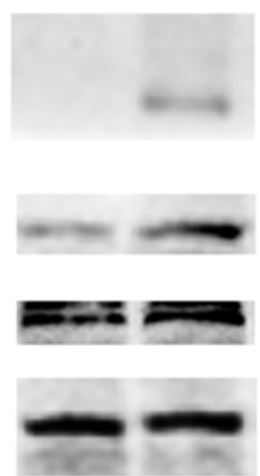

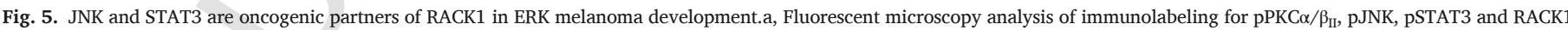

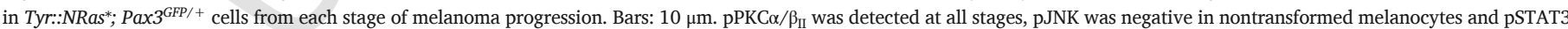

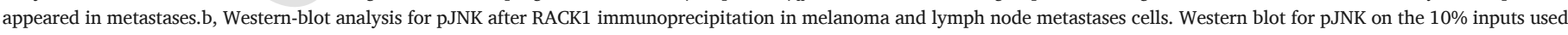

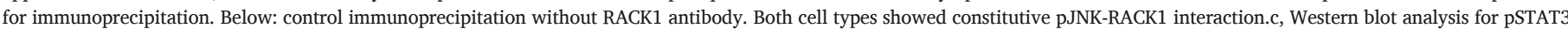

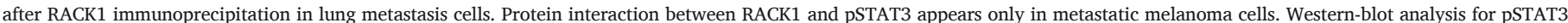
and STAT3 in primary melanoma and metastasis cells. Tubulin was used as loading control. 
tion was only detected in metastases (Fig. 5c). These data suggest that JNK and STAT3 are activated prior or during the metastatic process.

\subsection{Coordinated expression of RACK1, JNK and STAT3 regulates invasive potential}

To investigate RACK1, JNK and STAT3 coordination, we verified whether RACK1 levels were under c-Jun transcriptional control treating cells with a JNK inhibitor, SP600125. SP600125 reduced the levels of both $36 \mathrm{kDa}$ and $60 \mathrm{kDa}$ forms of RACK1 in all melanoma cells types (Fig. 6a). A reduction of pJNK was also found (Fig. 6a). When we compared FACS-sorted cells derived from primary melanomas of Tyr::Rack1-HA; Tyr::NRas*; Pax3 ${ }^{\text {GFP/+ }}$ mice with the ones from Tyr::NRas*; Pax $3^{G F P /+}$ mice, we observed pJNK immunoreactivity in Tyr::Rack1-HA melanoma cells not only in the nucleus but also in the cytosol (Fig. 6b). We reasoned that if RACK1 overexpression accelerated the appearance of tumorigenic properties, a correlation with JNK activity would be found in Tyr::Rack1-HA melanoma cells. To test this hypothesis we carried out clonogenic and JNK activity assays. In soft agar assay, cells overexpressing Rack1 started forming clones earlier than control cells (Fig. 6c). SP600125 treatment of Tyr::Rack1-HA melanoma cells prevented colony formation in agar over a 6 days period (Fig. 6c). When immunokinase assays using GST-c-Jun ${ }^{1-89}$ as substrate were performed on primary cells of melanomas, an increased JNK activity was revealed in Tyr::Rack1-HA melanoma cells compared to controls Tyr::NRas* (Fig. 6d). These data point to a stronger JNK activity in RACK1 overexpressing melanomas.

Out of 5 enhancer regions described by ENCODE and identified on human RACK1 genecard (www.genecards.org), three (GHO5E181172, GH05E181215, GH05E181240) present binding sites for STAT3. To test whether STAT3 transcriptionally regulates RACK1 in Tyr::NRas* cells, we transduced interfering lentiviral shStat 3 vectors. STAT3 knock-down in lung metastasis cells led to Rack1 mRNA (Fig. 6ei) and RACK1 protein reduction on both the $36 \mathrm{kDa}$ and the $60 \mathrm{kDa}$ bands (Fig. 6eii). STAT3 knock-down effect on RACK1 mRNA and protein levels was also effective in human UACC903 melanoma cell lines as illustrated in Fig. 6f. As the JNK pathway was shown to activate STAT3 in epithelial cells [21], we tested whether JNK was regulating STAT3 in melanoma cells. In agreement with above findings, pSTAT3 signal was reduced in SP600125-treated mouse cells (Fig. 6a). Inhibition of JNK activation did also reduce STAT3 activation in human melanoma cell lines (Fig. 6g).

In order to further dissect the mechanism engaged by RACK1 overexpression to allow melanoma cells to metastasize, we examined the transcriptome of melanoma cells from primary lesions in Tyr::NRas* and Tyr::Rack1-HA, Tyr::NRas* by RNA-seq. Ingenuity Pathway Analysis on numerically differentially expressed genes resulted in the enrichment of tissue morphology, cellular movement, growth and proliferation pathways. Stat3 appeared increased in Tyr::Rack1-HA, Tyr::NRas* with a fold change of 1.3. We intended to analyse the effect of shRack1. In these heterogeneous primary cultures, estimation of the efficacy of lentiviral vector transduction was around $50 \%$ for both shRack 1 and shScramble (Fig. 6h). By immunohistochemistry RACK1 protein downregulation was detected in the transduced cells (Fig. 6h) but no reduction of Rack1 mRNA was noticeable for any of the 6 transcripts of Rack1, from which only 2 (ENSMUST00000020640 and ENSMUST00000125166) can be translated. Among the genes that exhibited increased expression in Tyr::Rack1-HA, Tyr::NRas* cells and decreased expression following shRack1 treatment, Adgrg1 encoding the adhesion G protein-coupled receptor G1, has been shown to dually regulate angiogenesis during melanoma progression [22]. Quantitative RT-PCR on Rack1 exon 2, targeted by the interfering sequence, showed a slight reduction upon shRack1 treatment (Fig. 6i). Reduction of RACK1 was related to a clear decrease in Adgrg1 expression in melanoma cells from
Tyr::Rack1-HA, Tyr::NRas* and Tyr::NRas* mice. The Adgrg1 reduction was stronger on Tyr::Rack1-HA, Tyr::NRas* cells, in which Stat3 reduction was observed, in contrast to Tyr::NRas* cells (Fig. 6i). In agreement with these results, RACK1 knock-down in B16 cell agar colonies led to pSTAT3 reduction (Fig. 1dii). To test whether angiogenesis could be responsible for the clinical outcome of Tyr::Rack1-HA, Tyr::NRas* melanomas, we performed $\alpha$-smooth muscle actin ( $\alpha$ SMA) immunofluorescence on the mouse primary melanoma lesions of Tyr::Rack1-HA, Tyr::NRas* and Tyr::NRas* models. $\alpha$ SMA is a marker of myofibroblasts and pericytes used to identify capillaries and vascular structures. Fig. $6 \mathrm{j}$ shows the higher density of $\alpha \mathrm{SMA}^{+}$and vascularisation in heavily pigmented lesions in the Tyr::Rack1-HA genotype.

\section{Discussion}

RACK1 overexpression has been described in different solid cancers. Its detection in situ was proposed as a diagnostic marker in melanoma [2] and several carcinomas [23-25]. Many studies have shown that RACK1 is involved in multiple aspects of cancer progression in vitro (reviewed by [7]). As cell monolayers are far from in vivo complexity, we wanted to test whether the model, in which NRAS ${ }^{\mathrm{Q} 61 K}$ triggering ERK/ c-Jun accumulation with subsequent RACK1 increase and JNK activation, was valid in the mouse. In this study, we generated Tyr::Rack1-HA transgenic mice to test a RACK1 role in melanoma initiation and progression in vivo. Our results support the model of RACK1 as a major player in melanomagenesis.

We showed that transgenic Tyr::Rack1-HA mice overexpressed Rack1 in melanocytes with concomitant detection of pERK and pAKT. Nevertheless, Tyr::Rack1-HA mice did not develop either hyperpigmentation nor melanoma suggesting that additional alterations are required for both events. In Tyr::NRAS* transgenic mice, NRAS ${ }^{\mathrm{Q} 61 K}$ triggers MAPK and PI3K/AKT pathways activation [10]. This mutation leads to hyperproliferation of skin melanocytes and spontaneous melanoma development [11]. We showed here that these mice also overexpress RACK1 in melanocytes. Thus, the difference in phenotypes could be ascribed to a differential compartmentalization of the proteins in the two melanocyte-types engaging then distinct genetic programs [26]. Alternatively, it could hint at the existence of additional pathways triggered by the NRas ${ }^{Q 61 K}$ mutation, independent of ERK, JNK, AKT, STAT3 pathways and scaffold RACK1.

Breeding Tyr::Rack1-HA mice with Tyr::NRAS* mice enhanced melanoma initiation and progression, with reduced latency and increased incidence as well as distant metastases in three independent mouse lines. We provided a first evidence of a role for RACK1 in melanomagenesis in vivo.

RACK1 serves as a signaling hub that has been implicated in the regulation of several pathways. To identify proteins mediating a role for RACK1 in melanomagenesis, we determined the activation status of $\mathrm{PKC} \alpha / \beta_{\mathrm{II}}$, STAT3 and JNK in primary cultures. pPKC $\alpha / \beta_{\mathrm{II}}$ was detected since the early stages as described [2], whereas STAT3 and JNK proteins were found activated in all lymph node metastatic cells which are representative of the first metastatic stage. Clinically, improved therapy for melanoma will benefit from understanding the metastatic process at a molecular level. In our primary culture cells, JNK activation marked progression to lymph-node metastases. Fittingly, a pathology study showed JNK activation associated with poor prognosis [27]. However, an oncogenic role of the JNK/c-Jun pathway in melanoma development is still under debate [28]. The tumor suppressor $p 16 / C d$ $k n 2 a$ was reported to exert its inhibitory role on tumor cells by suppressing JNK activity [29]. In our system, Cdkn2a deletion was not sufficient alone to trigger JNK activation. Lopez-Bergami et al. described that RACK1 mediates JNK activation by PKC in vitro [5]. Moreover, in human melanoma cell lines, constitutively active ERK provides signals to increase the activity of JNK via a rewired signaling [9]. In the pri- 
a

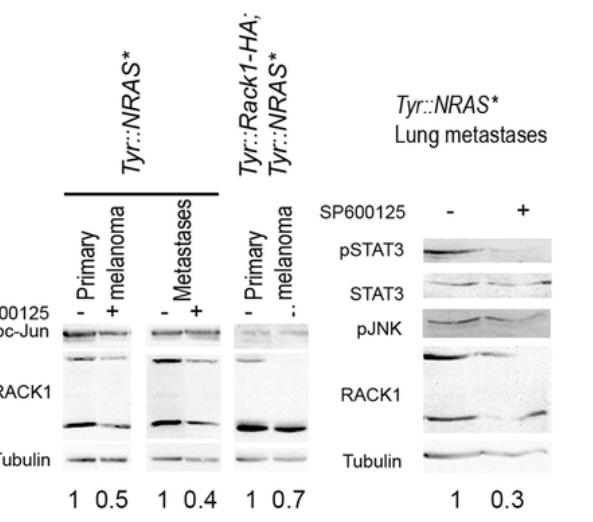

b

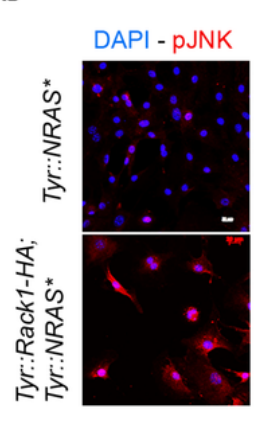

C Soft Agar Assay, day 6

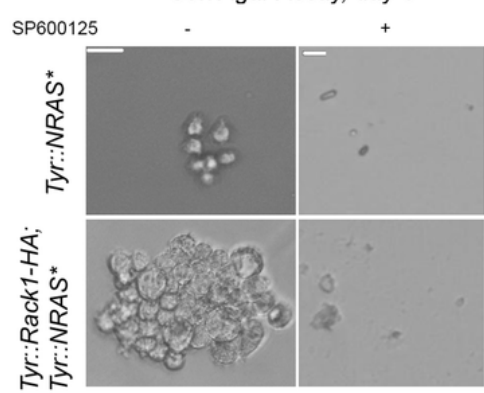

d

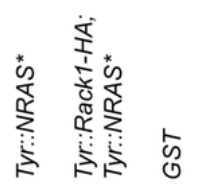

In vitro

kinase

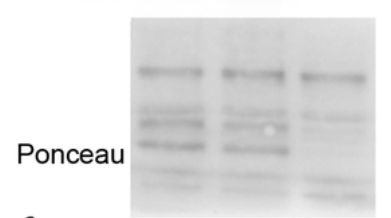

f i

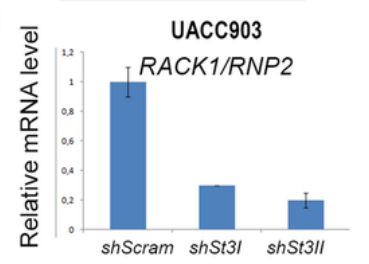

${ }^{32}$ P-GST-C-Jun ${ }^{1-89}$

GST-C-Jun $^{1-89}$

$\mathrm{e}_{\mathrm{i}}$

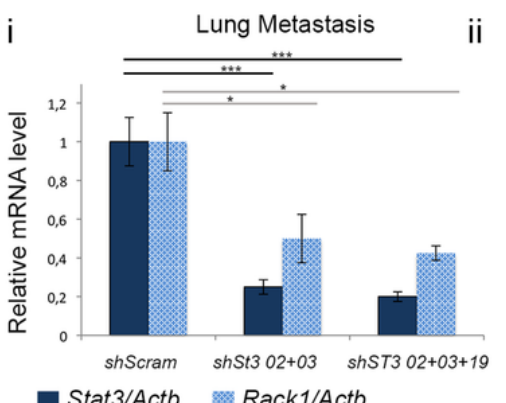

Lung Metastasis

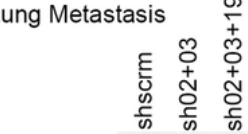

STAT3

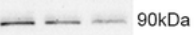

RACK1

$60 \mathrm{kDa}$

RACK1

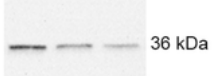

ii

Stat3/Actb

Nack1/Actb

Tubulin

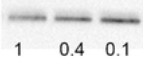

UACC903

shScram shSt3l shSt3ll

STAT3

RACK1

Actin

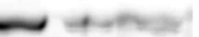

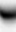

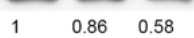

g

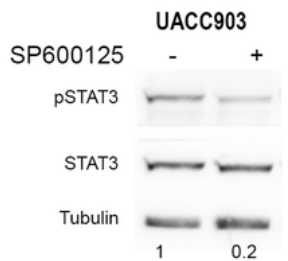

h
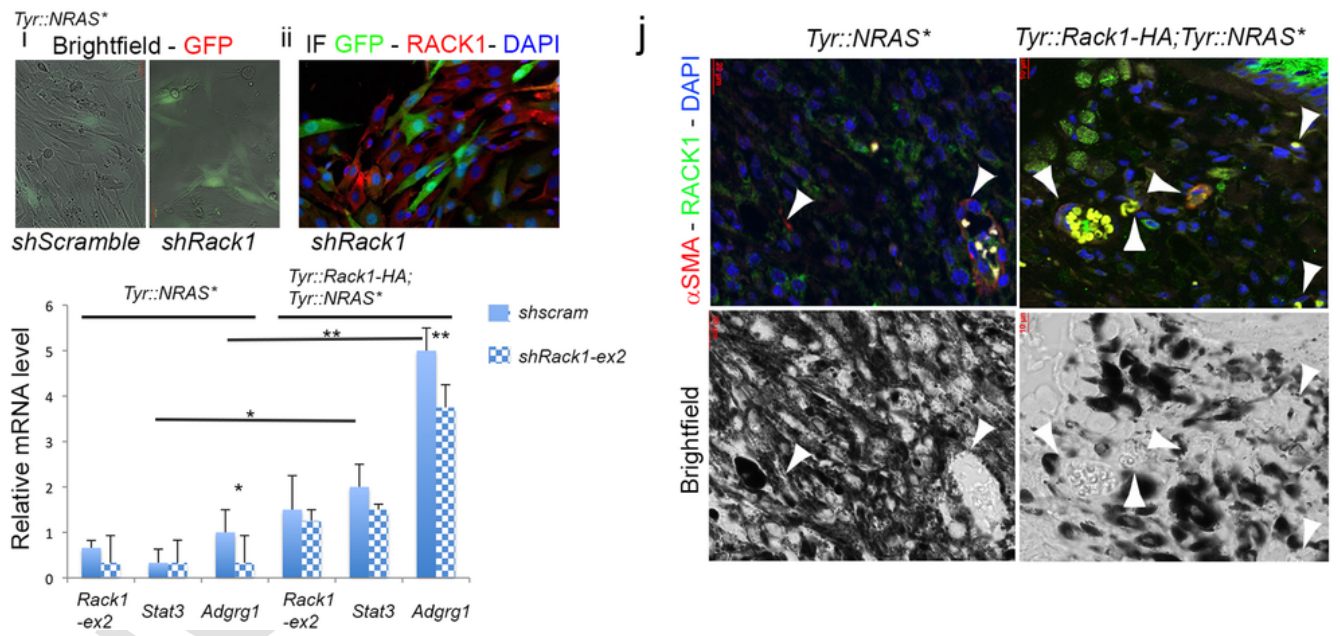

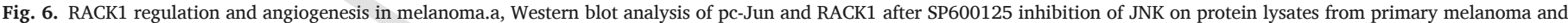

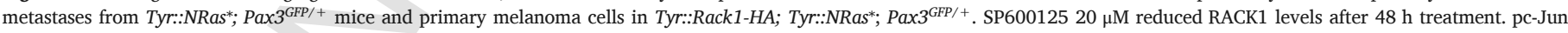

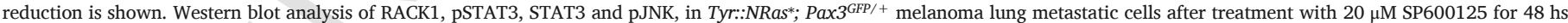

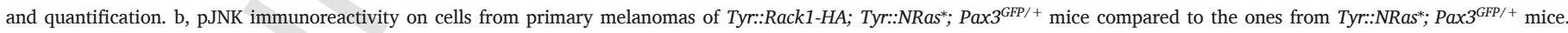

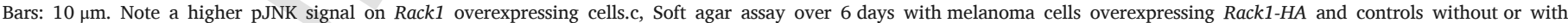

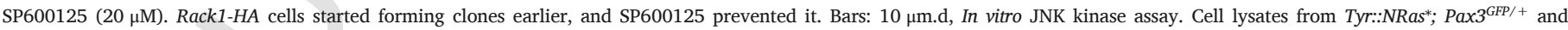

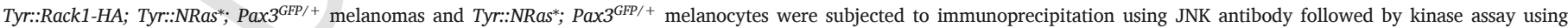

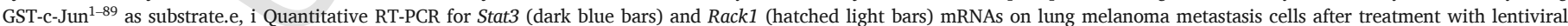

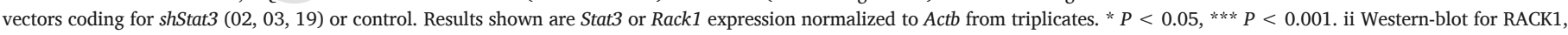

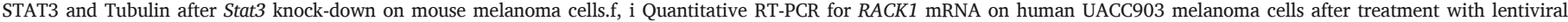

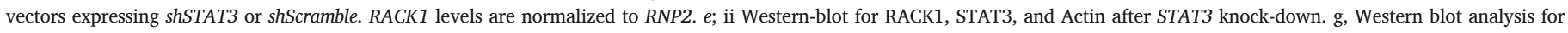




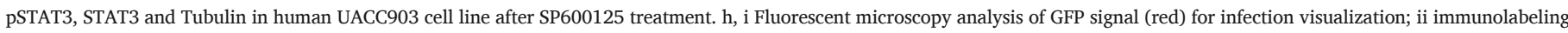

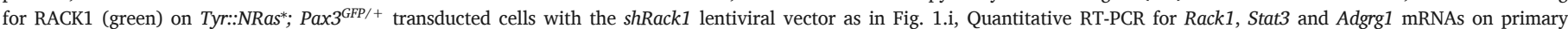

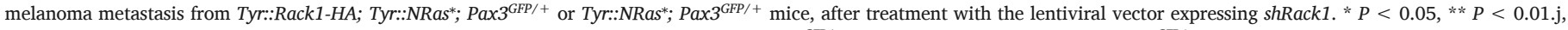

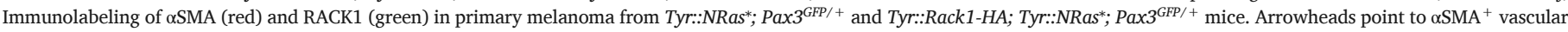

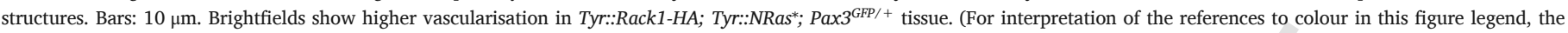
reader is referred to the web version of this article.)

mary melanoma cells from Tyr::Rack1-HA; Tyr::NRas*; Pax $3^{\text {GFP/+ }}$ mice, pJNK was detected both in the nucleus and cytoplasm. JNK activity was increased as determined in the kinase assay. Although we have not explored the underlying mechanism of JNK activation, our data support the previous in vitro model where JNK activation is being driven by PKC, ERK and RACK1. Data are consistent with the positive correlation observed between cytoplasmic pJNK and pERK in human melanomas [27], where RACK1 is overexpressed [2]. Phospho-STAT3 on Ser705 was mainly found in lymph-node metastatic cells, which is consistent with progressive activation found in human melanoma cell lines [20] [30] and in tumor samples. In melanoma cells, activated STAT3 was reported to sustain expression of the anti-apoptotic genes, Bcl-xL (Bcl2-like 1) and Mcl-1 (Myeloid cell leukemia sequence 1) [31]. Constitutive STAT3 activation might be a crucial event in metastasis development. We identified STAT3 as a direct RACK1 partner in melanoma development. Confirming the functional interaction between STAT3 and RACK1 we found that RACK1 was regulated at the mRNA level by STAT3. Noteworthy, STAT3-mediated maintenance of NF-kB activity occurs in human A2058 melanoma cell line [32]. In turn, NF- $\mathrm{BB}$ is known to upregulate the transcription of RACK1 through direct interaction with its promoter thus contributing to cell survival in PC12 cells [33]. Besides, inhibition of JNK activity led to decreased activation of STAT3. This was reported in colon cancer cells after treatment with AS601245, another JNK inhibitor [34].

B16 mouse melanoma cells harbor both STAT3 activation and JNK activation (data not shown). RACK1 silencing in B16 cell line led to reduced invasive capacities and cell differentiation and loss. The differentiated shape with dendritic extensions closely resembles the in situ status of melanocytes in normal skin where no RACK1 is detected [2,3]. Yet, our results seem to be in apparent contradiction with the recent publication of Marubashi et al. which showed that Rack1 knock-down in melan-a cells decreased their dendricity [35]. In fact, this specific phenotype corresponded to forskolin treated cells, and it might depend upon the extent of RNA silencing and the time before observation. Previous observations showed that mouse fibroblast cells with silenced RACK1 contained more and longer focal adhesions [18,19].

We observed an additional $60 \mathrm{kDa}$ band revealed by RACK1 antibody only in transformed cells, which does not appear in the literature. This band decreased in the presence of the JNK inhibitor or STAT3 knock down suggesting it could reflect a form of RACK1 related to malignancy. Further investigation must be carried out to understand the significance of this isoform.

RNA-seq data were produced in order to determine the targets of signaling pathways induced by RACK1 overexpression that cause the phenotype changes between normal and tumoral melanocytes with different potential. Tyr::Rack1-HA; Tyr::NRas* primary melanoma cells expressed a higher basal level of Adgrg1 mRNA. Interestingly, Adgrg1 has been related to angiogenesis [22] and RACK1 overexpressing melanomas did appear to contain more $\alpha \mathrm{SMA}^{+}$cells, a marker of angiogenesis. Adgrg1 activation was recently shown to promote melanoma migration [37]. Melanomas have a high angiogenic potential. These observations are in agreement with early findings on RACK1 expression during angiogenesis [38]. Biological replicates of tumors should be used to formulate new hypotheses on transcriptional targets of RACK1-involving pathways. The wide implication of RACK1 in physiological processes precludes the possibility to directly act on this protein [7]. Identification of RACK1-protein interactions holds the oppor- tunity to develop new therapeutics by the design of peptides interfering with specific binding partners of RACK1 $[39,40]$.

In summary, we demonstrated that RACK1 is implicated in melanomagenesis. RACK1 enhanced melanoma initiation and progression in vivo. We propose that activated STAT3 adds to JNK as RACK1 partners in the metastatic process. Specific interference between RACK1 and its partners must be further analysed as a potential therapeutic improvement in melanoma treatment.

Supplementary data to this article can be found online at http://dx. doi.org/10.1016/j.cellsig.2017.03.015.

\section{Authors contributions}

JJP, GEM designed the study, CC performed all studies on the mouse and mouse cell assays, MEP and PLB on human cell lines and the JNK assay, SL, PS performed mouse transgenesis, FB and ERG scored histological samples, JEz performed immunofluorescence, PHC carried out FACS, SP, UM provided lentiviral vectors expressing shRack1, GAH advised with constructs, DE, performed RNA-seq, JE bioinformatic analysis, EB converted gene names. CC and GEM wrote the manuscript.

\section{Uncited reference}

\section{Acknowledgements}

We wish to thank A. Casanova and C. Koenen for dedicated animal husbandry. We are grateful to A. Champeix and P. Wattier for sample inclusions in paraffin. We thank S. Bibi for technical help with qPCR. We thank Pierre Adenot (Microscopie et Imagerie des Microorganismes, Animaux et Aliments, MIMA2, INRA) for access to confocal microscopy facilities. We are thankful to Z. Ronaï for control plasmid used in preliminary experiments. We specially thank A. Eychene and N. Mach for helpful discussions and D. Milan for support. This work was funded by grants from Institut National de la Recherche Agronomique, INRA Crédits incitatifs du département de génétique animale (GEM), l'Agence Nationale de la Recherche Emergence Bio ANR 09-EBIO-006-01 to GEM, Ecos-Sud to JJP, GEM and PLB and Association pour la Recherche contre le Cancer (grants 99/7468 and 1002) to GAH and GEM. CC received a grant (Allocation de Recherche MENRT) from the Ministère de la Recherche et de l'Enseignement Supérieur. MEP received a grant from the CONICET.

\section{References}

[1] P.A. Ascierto, S. Agarwala, G. Botti, A. Cesano, G. Ciliberto, M.A. Davies, S. Demaria, R. Dummer, A.M. Eggermont, S. Ferrone, et al., Future perspectives in melanoma research: meeting report from the "Melanoma Bridge". Napoli, December 1st-4th 2015, J. Transl. Med. 14 (2016) 313.

[2] G. Egidy, S. Julé, P. Bossé, F. Bernex, C. Geffrotin, S. Vincent-Naulleau, V. Horak, X. Sastre-Garau, J.J. Panthier, Transcription analysis in the MeLiM swine model identifies RACK1 as a potential marker of malignancy for human melanocytic proliferation, Mol. Cancer 7 (2008) 34.

[3] C. Campagne, S. Julé, F. Bernex, M. Estrada, G. Aubin-Houzelstein, J.J. Panthier, G. Egidy, RACK1, a clue to the diagnosis of cutaneous melanomas in horses, BMC Vet. Res. 8 (2012) 95.

[4] C. Campagne, S. Julé, C. Alleaume, F. Bernex, J. Ezagal, S. Château-Joubert, M. Estrada, G. Aubin-Houzelstein, J.J. Panthier, G. Egidy, Canine melanoma diagnosis: RACK1 as a potential biological marker, Vet. Pathol. 50 (2013) 1083-1090. 
[5] P. López-Bergami, H. Habelhah, A. Bhoumik, W. Zhang, L.H. Wang, Z. Ronai, RACK1 mediates activation of JNK by protein kinase C [corrected], Mol. Cell 19 (2005) 309-320.

[6] D. Ron, C.H. Chen, J. Caldwell, L. Jamieson, E. Orr, D. Mochly-Rosen, Cloning of an intracellular receptor for protein kinase C: a homolog of the beta subunit of G proteins, Proc. Natl. Acad. Sci. U. S. A. 91 (1994) 839-843.

[7] D.R. Adams, D. Ron, P.A. Kiely, RACK1, a multifaceted scaffolding protein: structure and function, Cell Commun. Signal 9 (2011) 22.

[8] V. Volta, A. Beugnet, S. Gallo, L. Magri, D. Brina, E. Pesce, P. Calamita, F. Sanvito, S. Biffo, RACK1 depletion in a mouse model causes lethality, pigmentation deficits and reduction in protein synthesis efficiency, Cell. Mol. Life Sci. 70 (2013) 1439-1450.

[9] P. Lopez-Bergami, C. Huang, J.S. Goydos, D. Yip, M. Bar-Eli, M. Herlyn, K.S. Smalley, A. Mahale, A. Eroshkin, S. Aaronson, Z. Ronai, Rewired ERK-JNK signaling pathways in melanoma, Cancer Cell 11 (2007) 447-460.

[10] D.C. Bennett, How to make a melanoma: what do we know of the primary clonal events?, Pigment Cell Melanoma Res. 21 (2008) 27-38.

[11] J. Ackermann, M. Frutschi, K. Kaloulis, T. McKee, A. Trumpp, F. Beermann, Metastasizing melanoma formation caused by expression of activated N-RasQ61K on an INK4a-deficient background, Cancer Res. 65 (2005) 4005-4011.

[12] A. Camacho-Hübner, F. Beermann, Increased transgene expression by the mouse tyrosinase enhancer is restricted to neural crest-derived pigment cells, Genesis 29 (2001) 180-187.

[13] C. Campagne, E. Reyes-Gomez, S. Loiodice, S. Gadin, J. Ezagal, F. Bernex, M. Abitbol, A. Louise, F. Beermann, J.J. Panthier, et al., Haplosufficiency of PAX3 for melanoma development in Tyr: NRASQ61K; Cdkn2a - /- mice allows identification and sorting of melanoma cells using a Pax3GFP reporter allele, Melanoma Res. 26 (2016) 12-20.

[14] C. Campagne, E. Reyes-Gomez, M. Battistella, F. Bernex, S. Château-Joubert, H. Huet, F. Beermann, G. Aubin-Houzelstein, G. Egidy, Histopathological atlas and proposed classification for melanocytic lesions in Tyr:: NRas(Q61K); Cdkn2a $(-/-)$ transgenic mice, Pigment Cell Melanoma Res. 26 (2013) 735-742.

[15] M. Mourtada-Maarabouni, L. Kirkham, F. Farzaneh, G.T. Williams, Functional expression cloning reveals a central role for the receptor for activated protein kinase C 1 (RACK1) in T cell apoptosis, J. Leukoc. Biol. 78 (2005) 503-514.

[16] M.E. Avale, P. Faure, S. Pons, P. Robledo, T. Deltheil, D.J. David, A.M. Gardier, R. Maldonado, S. Granon, J.P. Changeux, U. Maskos, Interplay of beta2* nicotinic receptors and dopamine pathways in the control of spontaneous locomotion, Proc. Natl. Acad. Sci. U. S. A. 105 (2008) 15991-15996.

[17] J. Djian-Zaouche, C. Campagne, E. Reyes-Gomez, S. Gadin-Czerw, F. Bernex, A. Louise, F. Relaix, M. Buckingham, J.J. Panthier, G. Aubin-Houzelstein, Pax3(GFP), a new reporter for the melanocyte lineage, highlights novel aspects of PAX3 expression in the skin, Pigment Cell Melanoma Res. 25 (2012) 545-554.

[18] T. Vomastek, M.P. Iwanicki, H.J. Schaeffer, A. Tarcsafalvi, J.T. Parsons, M.J. Weber, RACK1 targets the extracellular signal-regulated kinase/mitogen-activated protein kinase pathway to link integrin engagement with focal adhesion disassembly and cell motility, Mol. Cell. Biol. 27 (2007) 8296-8305.

[19] H.C. O'Donovan, P.A. Kiely, R. O'Connor, Effects of RACK1 on cell migration and IGF-I signalling in cardiomyoctes are not dependent on an association with the IGF-IR, Cell. Signal. 19 (2007) 2588-2595.

[20] T.X. Xie, F.J. Huang, K.D. Aldape, S.H. Kang, M. Liu, J.E. Gershenwald, K. Xie, R. Sawaya, S. Huang, Activation of stat3 in human melanoma promotes brain metastasis, Cancer Res. 66 (2006) 3188-3196.

[21] B. Chen, J. Liu, Q. Chang, K. Beezhold, Y. Lu, F. Chen, JNK and STAT3 signaling pathways converge on Akt-mediated phosphorylation of EZH2 in bronchial epithelial cells induced by arsenic, Cell Cycle 12 (2013) 112-121.

[22] L. Yang, G. Chen, S. Mohanty, G. Scott, F. Fazal, A. Rahman, S. Begum, R.O. Hynes, L. Xu, GPR56 regulates VEGF production and angiogenesis during melanoma progression, Cancer Res. 71 (2011) 5558-5568.
[23] Z. Wang, B. Zhang, L. Jiang, X. Zeng, Y. Chen, X. Feng, Y. Guo, Q. Chen, RACK1, an excellent predictor for poor clinical outcome in oral squamous carcinoma, similar to Ki67, Eur. J. Cancer 45 (2009) 490-496.

[24] X.X. Cao, J.D. Xu, J.W. Xu, X.L. Liu, Y.Y. Cheng, W.J. Wang, Q.Q. Li, Q. Chen, Z.D. Xu, X.P. Liu, RACK1 promotes breast carcinoma proliferation and invasion/ metastasis in vitro and in vivo, Breast Cancer Res. Treat. 123 (2010) 375-386.

[25] S. Shi, Y.Z. Deng, J.S. Zhao, X.D. Ji, J. Shi, Y.X. Feng, G. Li, J.J. Li, D. Zhu, H.P. Koeffler, et al., RACK1 promotes non-small-cell lung cancer tumorigenicity through activating sonic hedgehog signaling pathway, J. Biol. Chem. 287 (2012) 7845-7858.

[26] A. Herrero, B. Casar, P. Colón-Bolea, L. Agudo-Ibáñez, P. Crespo, Defined spatiotemporal features of RAS-ERK signals dictate cell fate in MCF-7 mammary epithelial cells, Mol. Biol. Cell 27 (2016) 1958-1968.

[27] K. Jørgensen, B. Davidson, V.A. Flørenes, Activation of c-jun N-terminal kinase is associated with cell proliferation and shorter relapse-free period in superficial spreading malignant melanoma, Mod. Pathol. 19 (2006) 1446-1455.

[28] P. Lopez-Bergami, The role of mitogen- and stress-activated protein kinase pathways in melanoma, Pigment Cell Melanoma Res. 24 (2011) 902-921.

[29] B.Y. Choi, H.S. Choi, K. Ko, Y.Y. Cho, F. Zhu, B.S. Kang, S.P. Ermakova, W.Y. Ma A.M. Bode, Z. Dong, The tumor suppressor p16(INK4a) prevents cell transformation through inhibition of c-Jun phosphorylation and AP-1 activity, Nat. Struct. Mol. Biol. 12 (2005) 699-707.

[30] M. Sakaguchi, M. Oka, T. Iwasaki, Y. Fukami, C. Nishigori, Role and regulation of STAT3 phosphorylation at Ser727 in melanocytes and melanoma cells, J. Invest. Dermatol. 132 (2012) 1877-1885.

[31] G. Niu, T. Bowman, M. Huang, S. Shivers, D. Reintgen, A. Daud, A. Chang, A. Kraker, R. Jove, H. Yu, Roles of activated Src and Stat3 signaling in melanoma tumor cell growth, Oncogene 21 (2002) 7001-7010.

[32] H. Lee, A. Herrmann, J.H. Deng, M. Kujawski, G. Niu, Z. Li, S. Forman, R. Jove, D.M. Pardoll, H. Yu, Persistently activated Stat3 maintains constitutive NF-kappaB activity in tumors, Cancer Cell 15 (2009) 283-293.

[33] D.S. Choi, H. Young, T. McMahon, D. Wang, R.O. Messing, The mouse RACK1 gene is regulated by nuclear factor-kappa B and contributes to cell survival, Mol. Pharmacol. 64 (2003) 1541-1548.

[34] A. Cerbone, C. Toaldo, S. Pizzimenti, P. Pettazzoni, C. Dianzani, R. Minelli, E. Ciamporcero, G. Roma, M.U. Dianzani, R. Canaparo, et al., AS601245, an anti-inflammatory JNK inhibitor, and clofibrate have a synergistic effect in inducing cell responses and in affecting the gene expression profile in CaCo- 2 colon cancer cells, PPAR Res. 2012 (2012) 269751.

[35] S. Marubashi, N. Ohbayashi, M. Fukuda, A Varp-binding protein, RACK1, regulates dendrite outgrowth through stabilization of Varp protein in mouse melanocytes, J. Invest. Dermatol. 136 (2016) 1672-1680.

[36] X.J. Yang, S. Grégoire, A recurrent phospho-sumoyl switch in transcriptional repression and beyond, Mol. Cell 23 (2006) 779-786.

[37] N.Y. Chiang, Y.M. Peng, H.H. Juang, T.C. Chen, H.L. Pan, G.W. Chang, H.H. Lin, GPR56/ADGRG1 activation promotes melanoma cell migration via NTF dissociation and CTF-mediated G $\alpha 12 / 13 /$ RhoA signaling, J. Invest. Dermatol. (2016).

[38] H. Berns, R. Humar, B. Hengerer, F.N. Kiefer, E.J. Battegay, RACK1 is up-regulated in angiogenesis and human carcinomas, FASEB J. 14 (2000) 2549-2558.

[39] K.J. Smith, G.S. Baillie, E.I. Hyde, X. Li, T.M. Houslay, A. McCahill, A.J. Dunlop, G.B. Bolger, E. Klussmann, D.R. Adams, M.D. Houslay, 1H NMR structural and functional characterisation of a cAMP-specific phosphodiesterase-4D5 (PDE4D5) $\mathrm{N}$-terminal region peptide that disrupts PDE4D5 interaction with the signalling scaffold proteins, beta-arrestin and RACK1, Cell. Signal. 19 (2007) 2612-2624.

[40] M. Kiely, D.R. Adams, S.L. Hayes, R. O'Connor, G.S. Baillie, P.A. Kiely, RACK1 stabilises the activity of PP2A to regulate the transformed phenotype in mammary epithelial cells, Cell. Signal. (2016). 